\title{
Impact of integration through peer instructed lectures
}

\author{
Prapthi Persis Bathini*, Sumana Sen
}

Department of Pharmacology, Apollo institute of medical sciences and Research, Hyderabad, Telangana, India

Received: 24 April 2017 Accepted: 28 April 2017

\section{*Correspondence to:}

Dr. Prapthi Persis Bathini, Email: prapthi.b@gmail.com

Copyright: (C) the author(s), publisher and licensee Medip Academy. This is an openaccess article distributed under the terms of the Creative Commons Attribution NonCommercial License, which permits unrestricted noncommercial use, distribution, and reproduction in any medium, provided the original work is properly cited.

\begin{abstract}
Background: Integrated case based lectures are widely used as an effective method of teaching and learning. This method not only integrates all the disciplines in a particular year but also presents them in an effective case based format. Over the years, the students were less enthusiastic about this method. In order to make it more student centred and to actively involve them we have introduced peer case based integrated lectures. Peer assisted learning is a strong educational strategy known to benefit peer tutors and learners. This study evaluates the Knowledge gain of both the methods to see if there is any significant difference.
\end{abstract}

Methods: Students in their $2^{\text {nd }}$ year MBBS who agreed to participate were included in the study. After a series of discussions with the curriculum committee, the basic and clinical faculty, topics of public health importance were selected and written case scenarios with a set of relevant questions were formulated. In case based integrated lectures for tuberculosis, lectures were taken by faculty of the pertaining disciplines. In the peer case based integrated lectures on HIV, the same were taken by the students. A pre-test and post test was conducted after each session to know if there is a significant difference in knowledge gain in the two formats.

Results: For the case based and peer led case based lectures, the mean student attendance was $90 \%$ and $86 \%$. In the pre-test of integrated group on tuberculosis the mean score was 9.96 with standard deviation of 2.38 . The posttest of the same group, the mean knowledge score was 13.63 with standard deviation of 2.20. There was significant improvement in knowledge with the case based integrated lectures of 3.67 . The $p$ value $(0.0001)$ for this intervention is extremely significant. The post-test marks obtained for integrated and peer integrated group were $13.63 \pm 2.20$ and $15.86 \pm 2.39$ respectively. The mean increase in knowledge after peer case based integrated group was 6.1 when compared to increase in knowledge after case based integrated group which was 3.67.

Conclusions: Integrated case base lectures is an effective teaching learning tool which can be further made student centric by involving students as peer teachers. Peer teaching is a valuable methodology to engage learners as teachers to improve their knowledge and communication skills as well creating an environment in which the peer audience will likely actively discuss and exchange ideas. Peer assisted learning is need of time to increase critical reasoning skills of medical students.

Keywords: Case based integrated lectures, Integration, Peer case based integrated lectures, Peer assisted learning

\section{INTRODUCTION}

The process of learning is complex one which involves mental activities linked to problem solving, generation of ideas, integration and critical thinking. There is a term 'Best Evidence Medical Education' (BEME) which is an initiative in the field of health professional education. ${ }^{1}$ Evolving needs of the society, innovations in medical 
education technology along with changing pattern of pathological scenarios necessitate a change in teaching of a medical graduate. The educational objectives should focus on how to integrate, to apply gathered information to analyze, generate and prioritize a differential diagnosis for a particular individual. Varied educational strategies have come up to satisfy these needs. They are combination of didactic lectures with case based learning (CBL), integrated learning programmes, problem based learning (PBL), early clinical exposure (ECE) ${ }^{2,3}$

An integrated approach is a strong educational strategy., 4 Integrated medical curriculum helps graduates to put together the learned facts so as to get the whole picture and adopt a holistic approach while treating a patient or planning a health care strategy. ${ }^{6}$ It has been reported from studies that information presented in an integrated manner with clinical relevance captures students' attention and creates excitement in learning. ${ }^{7}$

It has also been observed that students trained in an integrated curriculum made more accurate diagnoses than the students trained in a conventional curriculum. ${ }^{8}$

Case-based teaching (CBT)/case based lectures is a teaching learning technique which is interactive, provides increased motivation among students for learning by using clinical scenarios, and develops clinical reasoning process. $^{9}$

This method initially was received very well by the students, however over the years, the students were less enthusiastic about it. There was a drop in student participation in the discussion and lack of interest among the students. In order to overcome this, peer case based integrated lectures were devised. It is a combination of integration and peer learning in which the students present take the integrated lectures.

Peer assisted learning (PAL) is an active learning strategy. ${ }^{10} \mathrm{PAL}$ is described as a process in which "people from similar social groupings who are not professional teachers help each other to learn and learn themselves by teaching. ${ }^{11}$ The peer tutors and learners have been shown to benefit significantly in this learning environment, not only in the acquisition of theoretical knowledge and motor skills but also in the development of communication skills. ${ }^{12,13}$ It has also been shown to develop communication and professional skills. ${ }^{14}$

This study was done to compare the knowledge gain and the application of concepts after the traditional integrated case based lectures and peer case based integrated lectures.

\section{METHODS}

The study was done at Apollo Institute of Medical Sciences and Research for the second-year medical students (batch of 99 students) in the 5th semester of their
MBBS curriculum. Prior to initiation, due clearances were obtained from Institutional Ethics Committee. Experimental pre-test/post-test study was conducted with ninety-nine students of the second MBBS (5th semester) students for two topics of public health importance. Integrated case based lectures were scheduled once every week for two hours.

The committee for integration was formed with a group of faculties from preclinical, para clinical, clinical departments and student representatives with guidance of curriculum committee. Clinical Cases for integration were selected based on the importance of the clinical condition and its public health relevance. Emphasis was also laid on the importance of the clinical cases based on subjects like Pharmacology, Pathology, Microbiology and also Medicine. The case as well as the learning objectives/outcomes were formulated, by paraclinical departments. Constant endeavor was made to integrate them horizontally and vertically among different specialities.

Written case scenarios based on real patients were formulated. Each case was accompanied by a set of relevant questions to stimulate a focused enquiry and self-directed learning/reasoning.

All the students were give the case handouts, learning objectives and questions pertaining to the case 48-72 hrs prior. The first integrated topic on tuberculosis was done as a case based integrated lecture. The session was of two-hour duration. These lectures were taken by the faculty members of basic sciences and clinical departments relevant to the case. Integration of the content of lectures was achieved with elaborate discussion on the questions based on learning objectives. Pre-test and post test was conducted to assess the Knowledge comprehension and understanding of the topic.

The second integrated topic on HIV was conducted as peer case based integrated lecture. The students were sensitized about the new methodology. In this method, the lectures were taken by the students who prepared for the same under the guidance of the faculty. The students presented, discussed and interacted with the large peer group. The student audiences as well as the peer instructor were encouraged to ask questions. This was followed by a summing up session and few questions by a faculty from the relevant discipline. Pre-test and post test was conducted to assess the Knowledge comprehension and understanding of the topic.

\section{Assessment}

The knowledge levels or cognitive gains in the students before and after the traditional case based integrated learning program and the peer case based integrated program are assessed. Pre-test and post-test assessment with a set of 20 MCQs are given to the students before 
and after the integrated lectures. Questions were framed in such a way that they were similar in aspects of level of difficulty, knowledge/ recall and application. This was done to ensure uniformity. The data was analyzed using Student's t-test.

\section{Statistical analysis}

Student $\mathrm{t}$ test was used to analyze the results of pre-and post-test to analyze the significant gain in knowledge levels.

\section{RESULTS}

Student performance was evaluated by comparing the scores of pre-test and post-test between the traditional and peer led integrated lectures. The goal is to determine if there was significant difference in student performance.

For the case based and peer led case based lectures, the mean student attendance was $90 \%$ and $86 \%$. The pre-test and post test results of students were assessed by the student $\mathrm{t}$ tests (Table 1).

Table 1: The pre-test and post-test results of case based integrated lectures and peer case based integrated lectures.

\begin{tabular}{|llll|l|}
\hline Method & Pre-test Mean \pm SD & Post-test Mean \pm SD & Mean increase in knowledge & P value \\
\hline Case based integrated lectures & $9.96 \pm 2.38$ & $13.63 \pm 2.20$ & 3.67 & 0.0001 \\
\hline $\begin{array}{l}\text { Peer case based integrated } \\
\text { lectures }\end{array}$ & $9.76 \pm 3.01$ & $15.86 \pm 2.39$ & 6.1 & 0.0001 \\
\hline
\end{tabular}

The results show that in the pre-test of integrated group on tuberculosis the mean score was 9.96 with standard deviation of 2.38. In the post-test of the same group, the mean knowledge score was 13.63 with standard deviation of 2.20. There was significant improvement in knowledge with the case based integrated lectures of 3.67. The $p$ value $(0.0001)$ for this intervention is extremely significant.

In the peer case based integrated lecture on HIV, the pretest score was 9.76 with standard deviation of 3.01. The post-test of the same group the mean knowledge score 15.86 with standard deviation of 2.39. The $\mathrm{p}$ value (0.0001) for this intervention is extremely significant

The post-test marks obtained for integrated and peer integrated group were $13.63 \pm 2.20$ and $15.86 \pm 2.39$ respectively. The mean increase in knowledge after peer case based integrated group was 6.1 when compared to increase in knowledge after case based integrated group which was 3.67. There is a significant improvement in knowledge gain after the new format was introduced.

\section{DISCUSSION}

The present system of medical education is highly compartmentalized into individual subjects with very little integration on specific topics. An integrated teaching offers the advantage of simplification of basic sciences and taught with clinical sciences which enhances learning and provides a holistic picture. ${ }^{15}$

Integrated Case based lectures have been proved as an effective method which improved clinical reasoning skills, increased the competence of the students while motivating them to learn better. ${ }^{16}$ The shortcoming remains a component of passivity, wherein motivation and confidence might be difficult to achieve.

The teaching learning methods followed are predominantly teacher centric and there is a need for it to be changed to student centric so as to encourage selfdirected learning and active participation. Active learning on the other hand can produce meaningful learning, improve attitudes toward learning, increase knowledge and retention, and motivate the students to become selfregulated, confident and independent learners. ${ }^{17}$

The gain in knowledge after both the methods is statistically significant and both the methods were effective teaching learning methods. Baseline knowledge as estimated by the pre-test values was similar in both the groups.

Knowledge comprehension and understanding of the topic were assessed based on post-test scores and it was significantly higher in the peer group integrated lectures. The mean knowledge gain by students after peer case based integrated learning program was higher than that of the traditional integrated learning program.

This reflects that active participation by the students results in better retention of knowledge and understanding of the subject. Evidence from different educational settings show that peer teaching benefits both the peer teachers and the learners. ${ }^{18}$

In the traditional integrated group, students did not show much active participation in the discussion and in answering the questions, whereas in the peer led integrated group, students participated well in the discussion and answered most of the questions posed by the peer instructors as well as the faculty. 
This is in conjunction with the study that shows the Social compatibility between peer teachers and the learners results in creating a comfortable and safe environment for learners that promotes a free flow exchange of ideas. ${ }^{19}$

The limitation of the study was that it does not include student and faculty feedback which is a very valuable input in building up the program and it would be done in future sessions.

\section{CONCLUSION}

Integrated case base lectures is an effective teaching learning tool which can be further made student centric by involving students as peer teachers. Peer led Integrated teaching learning sessions are well appreciated.

Peer teaching is a valuable methodology to engage learners as teachers to improve their knowledge and communication skills as well creating an environment in which the peer audience will likely actively discuss and exchange ideas. This helps in retention of knowledge and better application of the concepts. Adaptation of new student centered teaching learning strategies is need of time to increase critical reasoning skills of medical students.

Funding: No funding sources

Conflict of interest: None declared

Ethical approval: The study was approved by the Institutional Ethics Committee

\section{REFERENCES}

1. Best Evidence Medical Education (BEME). Report of Meeting: 3-5 December 1999, London, UK. Med Teach. 2000;22:242-5.

2. Vyas R, Jacob M, Faith M, Isaac B, Rabi S, Sathishkumar $\mathrm{S}$, et al. An effective integratedlearning programme in the first year of the medical course. Natl Med J India. 2008,21:21-6.

3. Sathishkumar S, Thomas N, Tharion E, Neelkantan N, Vyas R. Attitude of medical students towards Early Clinical Exposure in learning endocrine physiology. BMC Med Edu. 2007;7:30.

4. Schmidt H. Integrating the teaching of basic sciences, clinical sciences and biopsychosocial issues. Acad Med. 1998;73(9):24-31.

5. Harden RM. The integration ladder: A tool for curriculum planning and evaluation. Med Educ. 2000;4:551-7.

6. Malik AS, Malik RH. Twelve tips for developing an integrated curriculum. Med Teach. 2011;33:99-104.
7. Custers EJ, Cate OT. Medical students' attitudes towards and perception of the basic sciences: a comparison between students in the old and the new curriculum at the University Medical Center Utrecht, The Netherlands. Med Educ. 2003;36:1142-50,

8. Schmidt HG, Machiels-Bongaerts M, Hermans H, ten Cate TJ, Venekamp R, Boshuizen HP. The development of diagnostic competence: comparison of a problem-based, an integrated, and a conventional medical curriculum. Acad Med. 1996;71:658-64.

9. Kassirer JP. Teaching clinical reasoning: case-based and coached. Acad Med. 2010;85:1118-24.

10. Henning JM, Weidner TG, Marty MC. Peer Assisted Learning in Clinical Education: Literature Review. Athlet Train Educat J. 2008;3:84-90.

11. Topping KJ. The effectiveness of peer tutoring in further and higher education: A typology and review of the literature. In: Goodlad S, editor. Mentoring and Tutoring by Students. London, Kogan Page; 1998.

12. Fantuzzo JW, Riggio RE, Connelly S, Dimeff LA. Effects of reciprocal peer tutoring on academic achievement and psychological adjustment: A component analysis. J Educ Psychol. 1989;81:173-7.

13. Ensergueix JP, Lafont L. Reciprocal peer tutoring in a physical education setting: Influence of peer tutor training and gender on motor performance and selfefficacy outcomes. Eur J Psychol Educ. 2010;25:22242.

14. Tai J, Molloy E, Haines T, Canny B Same-level peerassisted learning in medical clinical placements: a narrative systematic review. Med Educ. 2016;50(4):469-84.

15. Haranath P. Integrated teaching in medicine - Indian scene. Indian J Pharmacol. 2013;45:1-3.

16. Jamkar AV, Yemul VL, Singh G. Integrated teaching program with student centered case base learning for undergraduates at BJ Medical College Pune. Available on www. Faimer. com. 2016.

17. Wilke RR. The effect of active learning on student characteristics in a human physiology course for nonmajors. Adv Physiol Educ. 2003 Dec;27(14):207-23.

18. Benè KL, Bergus G. When Learners Become Teachers: A Review of Peer Teaching in Medical Student Education. Fam Med. 2014;46(10):783-7.

19. Nelson AJ, Nelson SV, Linn AMJ, Raw LE, Kildea HB, Tonkin AL. Tomorrow's educators today? Implementing near-peer teaching for medical students. Med Teach. 2013;35(2):156-9.

Cite this article as: Bathini PP, Sen S. Impact of integration through peer instructed lectures. Int $\mathbf{J}$ Basic Clin Pharmacol 2017;6:1293-6. 